\title{
Determinants associated with high-risk fertility behaviours among reproductive aged women in Bangladesh: a cross-sectional study
}

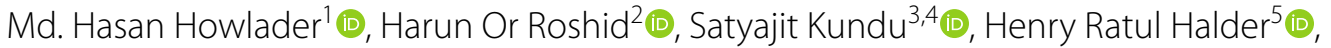
Sanjoy Kumar Chanda ${ }^{6}$ and Md. Ashfikur Rahman ${ }^{7^{*}}$ (D)

\begin{abstract}
Background: We aimed to determine the factors that increase the risk of HRFB in Bangladeshi women of reproductive age 15-49 years.

Methods: The study utilised the latest Bangladesh Demographic and Health Survey (BDHS) 2017-18 dataset. The Pearson's chi-square test was performed to determine the relationships between the outcome and the independent variables, while multivariate logistic regression analysis was used to identify the potential determinants associated with HRFB.

Results: Overall $67.7 \%$ women had HRFB among them $45.6 \%$ were at single risk and $22.1 \%$ were at multiple highrisks. Women's age (35-49 years: $\mathrm{AOR}=6.4295 \% \mathrm{Cl} 3.95-10.42)$, who were Muslims( $\mathrm{AOR}=5.52,95 \% \mathrm{Cl} 2.25-13.52)$, having normal childbirth ( $A O R=1.47,95 \% \mathrm{Cl} 1.22-1.69)$, having unwanted pregnancy $(A O R=10.79,95 \% \mathrm{Cl} 5.67-$ 18.64) and not using any contraceptive methods ( $A O R=1.37,95 \% \mathrm{Cl} 1.24-1.81$ ) were significantly associated with increasing risk of having HRFB. Alternatively, women and their partners' higher education were associated with reducing HRFB.

Conclusion: A significant proportion of Bangladeshi women had high-risk fertility behaviour which is quite alarming. Therefore, the public health policy makers in Bangladesh should emphasis on this issue and design appropriate interventions to reduce the maternal HRFB.
\end{abstract}

Keywords: High-risk fertility behaviour, Reproductive age, Women, Determinants, Bangladesh

\section{Plain Language Summary}

High rates of maternal high-risk fertility behaviour (HRFB) have a variety of unfavourable repercussions for both the mother and the child. However, because there have been few studies on this topic to date, we set out to identify the determinants that enhance the risk of HRFB in Bangladeshi women between the ages of 15 and 49 . Using latest demographic and health survey (BDHS) data we have found that $67.7 \%$ of women had HRFB, with $45.6 \%$ having a single high-risk factor and $22.1 \%$ having multiple high-risk factors. This high prevalence rate demonstrates that HRFB are all too common in Bangladesh, potentially endangering the health of the country's women. We found that women

*Correspondence: ashfikur@ku.ac.bd

${ }^{7}$ Development Studies Discipline, Khulna University, Khulna 9208, Bangladesh

Full list of author information is available at the end of the article permits use, sharing, adaptation, distribution and reproduction in any medium or format, as long as you give appropriate credit to the original author(s) and the source, provide a link to the Creative Commons licence, and indicate if changes were made. The images or other third party material in this article are included in the article's Creative Commons licence, unless indicated otherwise in a credit line to the material. If material is not included in the article's Creative Commons licence and your intended use is not permitted by statutory regulation or exceeds the permitted use, you will need to obtain permission directly from the copyright holder. To view a copy of this licence, visit http://creativecommons.org/licenses/by/4.0/. The Creative Commons Public Domain Dedication waiver (http://creativeco mmons.org/publicdomain/zero/1.0/) applies to the data made available in this article, unless otherwise stated in a credit line to the data. 
practicing Islam as core religion, age above 35 years, having normal childbirth, having above 3 children, having unwanted pregnancies and not using birth control methods were at increased risk of having HRFB. As a result of the study's findings, interventions are urgently needed to prevent high-risk fertility behaviour among Bangladeshi women aged 15 to 49 years.

\section{Background}

Women's high-risk fertility behaviour (HRFB), which is defined by "narrow birth intervals, high birth order, and younger maternal age at birth, have been associated with negative health outcomes for both the mother and the child" $[1,2]$. Maternal HRFB is a bio-demographic risk factor that impedes the achievement of lower maternal and child morbidity and mortality [3-7]. Some demographic variables, such as women's age, parity, and birth spacing are the crucial parameters of measuring HRBF including too-early ( $<18$ years) or too-late ( $>34$ years) childbearing, short birth intervals $(<24$ months $)$ and a higher number of live births (4 or higher) $[3,4,7,8]$. Although the total fertility rate (TFR) of Bangladesh declined from 3.7 in 1995 to 2.04 in 2020 [9]. Remarkably the rate of teenage pregnancy is about $35 \%$ and $15.1 \%$ gave birth less than 24 months interval in Bangladesh. Comparing with many developing countries Bangladesh has the highest rates of adolescent fertility with 82 births per 1000 women as of 2019 where over 50 percent of adolescents gave birth between the years 15-19 [10].

Several studies identified that early or late motherhood is associated with hypertension, premature labor, anemia, gestational diabetes, diabetes, obesity, pregnancy related complications, higher rates of caesarean and operative deliveries and unsafe abortions [11, 12]. Childbearing at an early age $(<18$ years) is connected to a growing risk of intrauterine growth restriction, child undernutrition, preterm birth, and infant mortality. On the other hand, late motherhood ( $>34$ years) is related to preterm births, intrauterine growth restriction, stillbirths, amniotic fluid embolism, chromosomal abnormalities and lowbirth-weight newborns [12, 13]. HRFB in mothers also associated with the neonatal mortality; while a study in India identified causal effect of birth spacing on neonatal mortality [14], and also childbearing at teenage was also found to be linked to neonatal mortality [15].

Some previous studies established a relationship between numerous HRFB-related parameters and their detrimental effects on maternal and infant health $[7,8$, $16,17]$. Women who start having children at an early age often have more children [18] and this is also associated with adverse maternal, infant and child health outcomes [19]. One the other hand, short birth intervals ( $<24$ months) [20] and higher birth order [21] may also aggravate the infant and child mortality. Although such evidence supports the consideration of different exposures to high-risk fertility behaviors as a high-priority maternal and child health concern, very few studies in Bangladesh have evaluated factors related to HRFB in women of reproductive age. Therefore, in order to develop effective prevention programs for the region, a clear understanding of the determinants and potential risk factors for maternal high-risk fertility behavior among Bangladeshi women is required. There is, however, a dearth of literature examining the risk factors for HRFB in Bangladesh. To date, most of the studies on HRFB in Bangladesh focused on identifying the relationship between HRFB in women, and maternal and child health outcome $[7,17,22]$. Based on these considerations, this study aimed to identify the associated factors of HRFB in women. Identifying such determinants will be crucial for formulating evidence-based programs in Bangladesh especially targeting the significant risk factors.

\section{Methods \\ Data sources}

The study relied on data from the Bangladesh Demographic and Health Survey 2017-18. The National Institute of Population Research and Training (NIPORT) of the Ministry of Health and Family Welfare of Bangladesh used a two-stage stratified sampling approach to conduct this cross-sectional study. The outcomes of our study were assessed using a total sample of 7757 women (age 15 to 49). The study included ever-married women aged 15-49 who were not pregnant currently and had at least one child before the survey. Unmarried and pregnant mothers with incomplete BMI information were excluded as the sample. The description about the data collection procedures and sampling frame are detailed in the original (BDHS 2017-18) report [23].

\section{Outcome variable}

The outcome variable for this study took into account maternal "high-risk fertility behaviour" developed using the definition of the BDHS [23]. The study considered three variables to define the high-risk-fertility behaviour: (a) maternal age at the time of delivery, (b) birth order, and (c) birth interval. The presence of any of the following conditions was termed as a single high-risk fertility behaviour: (i) mothers age less than 18 years at the time 
of childbirth (ii) mothers age over 34 years at the time of childbirth (iii) latest child born less than 24 months after the previous birth; and (iv) latest child's birth order 3 or higher. Multiple high-risk categories are made up of two or more aforesaid conditions. High-risk fertility behaviour was defined as the presence of any of the four conditions listed above (coded as 1 and otherwise 0 ) for final analysis.

\section{Independent variables}

The researchers reviewed the most recent relevant articles to determine the independent variables. The selected sociodemographic and economic variables (independent) included in the analysis are: place of residence (urban and rural), administrative division (Barishal, Chottogram, Dhaka, Khulna, Mymensingh, Rajshahi, Rangpur, Sylhet), religion (Islam, Hindu and other), age (15-24, 25-34 and 35-49 years), age at marriage $(<18$ and $\geq 18$ years), education (no education, primary, secondary and higher), access to television (no and yes), body mass index (according to WHO [24]; underweight: $<18.50 \mathrm{~kg} / \mathrm{m}^{2}$, normal: $18.50-24.99 \mathrm{~kg} / \mathrm{m}^{2}$, overweight/obese: $\geq 25.00 \mathrm{~kg} / \mathrm{m}^{2}$ ), current working status (currently working and not working), partner's education (no education, primary, secondary, higher); partner's occupation (agricultural, business, non-agricultural, other). Reproductive factors: birth order $(1-2,>3)$, antenatal care (ANC) seeking (no, yes) and current use of contraceptive methods (yes, no), types of childbirth (normal, caesarean), place of childbirth (home, facility birth), pregnancy wanted (then, later, no more).

\section{Statistical analysis}

The frequency and percentage of the selected attributes were determined using descriptive statistics. The Pearson's chi-square test was performed to show the association between the outcome variables and the specified independent variables at the bivariate level. Finally, the factors related to "high-risk fertility behaviour" were determined using a logistic regression analysis with significant components ( $\mathrm{p}$-values $<0.05)$ at the multivariate model. These analyses included both unadjusted odds ratios (UORs) and adjusted odds ratios (AORs) along with 95\% confidence intervals (CIs). Multicollinearity among covariates was checked for all models using variance inflation factors (VIFs), which were determined to be the modest with VIF $\leq 2$ for all covariates. Statistical package for social sciences (SPSS. 25.0) was used to conduct all statistical analyses.

\section{Ethical consideration}

DHS data is available in the public domain and is freely available to anyone who makes a reasonable request. The entire study protocol was approved by the Bangladesh Ethics Committee and ICF International; thus, we did not need any additional ethical approval. The BDHS 2017-18 report contains details about the ethical approval [23].

\section{Results}

\section{Background characteristics and prevalence of HRFB}

The final study included 7757 women who had given birth within the previous five years. The median (IQR) age of the respondents was 25.0 years (25.0-75.0). More than half (56.8\%) of the women aged 15 to 24 years. Most women $(71.6 \%)$ lived in rural areas, and overwhelmingly large number (90.5\%) of them were Muslims. Over half of the women finished secondary education and $62.8 \%$ were unemployed (Table 1).

The worst situation was found in the rural areas for both the single and multiple HRFB. About $46.7 \%$ of respondents from rural areas had single HRFB compared to $11.7 \%$ from urban areas. Similarly, $24.5 \%$ of women from rural areas were at multiple HRFB, which was only $4.4 \%$ among women from urban areas (Fig. 1). Figure 2 demonstrates the prevalence of HRFB across different administrative divisions of Bangladesh. The highest prevalence of single risk fertility behaviour was found in Dhaka (10.5\%), followed by Chottogram division (9.7\%). However, the highest rate of multiple HRFB was found in Chottogram division.

\section{Reproductive characteristics and high-risk fertility behaviour}

Most women (63.8\%) have had a recent normal childbirth and $54.3 \%$ have given birth at a healthcare center. Of the total mothers, a significant portion (91.9\%) completed ANC follow-up for their recent pregnancy (Table 2).

\section{Factors associated with high-risk fertility behaviour}

Both univariate and multivariate logistic regression models were used to identify potential risk variables, however because this model was controlled for confounding effects of covariates, we only used the adjusted results to interpret the findings. The women who were Muslims having higher risk of Fertility behavior (Adjusted Odds Ratio $[\mathrm{AOR}]=5.52$, 95\% Confidence Interval $[\mathrm{CI}] 2.25-$ 13.52, $\mathrm{p}<0.001)$ than that of other religion. HRFB was found $19 \%$ less common in younger women (15-24 years; $\mathrm{AOR}=0.19,95 \% \mathrm{CI} 0.10-0.30, \mathrm{p}<0.001)$ and 6.42 times more likely in women over 35 years $(\mathrm{AOR}=6.4295 \%$ CI $3.95-10.42, \mathrm{p}<0.001)$. Women who had normal childbirths possessed higher HRFB (AOR $=1.47,95 \%$ CI $1.22-1.69, \mathrm{p}=0.003)$ compared to those who had a caesarean section. Women who had unwanted pregnancies were 10.79 times more likely to have high-risk fertility than women whose pregnancies were desired 
Table 1 Background characteristics and bivariate distribution of high-risk fertility behaviour of study participants across different socio-economic variables $(n=7757)$

\begin{tabular}{|c|c|c|c|c|c|}
\hline \multirow[t]{2}{*}{ Variables } & \multicolumn{2}{|c|}{ High-risk fertility problem } & \multirow[t]{2}{*}{ Total (\%) } & \multirow[t]{2}{*}{ Chi-square value } & \multirow[t]{2}{*}{ P-value } \\
\hline & No & Yes & & & \\
\hline Administrative division & & & & 63.463 & $<0.001$ \\
\hline Barishal & $126(38.8)$ & $199(61.2)$ & $325(5.4)$ & & \\
\hline Chottogram & $445(37.2)$ & $752(62.8)$ & $1197(19.9)$ & & \\
\hline Dhaka & $737(47.5)$ & $816(52.5)$ & $1553(25.9)$ & & \\
\hline Khulna & $238(39.2)$ & $369(60.8)$ & $607(9.4)$ & & \\
\hline Mymensingh & $196(40.4)$ & $289(59.6)$ & $485(8.1)$ & & \\
\hline Rajshahi & $257(35.4)$ & $468(64.6)$ & $725(12.1)$ & & \\
\hline Rangpur & $219(34.2)$ & $422(65.8)$ & $641(10.7)$ & & \\
\hline Sylhet & $219(46.8)$ & $249(53.2)$ & $468(7.8)$ & & \\
\hline Place of residence & & & & 39.870 & $<0.001$ \\
\hline Urban & $800(47.0)$ & $903(53.0)$ & $1703(28.4)$ & & \\
\hline Rural & $1637(38.1)$ & $2660(61.9)$ & $4297(71.6)$ & & \\
\hline Religion & & & & 40.736 & $<0.001$ \\
\hline Islam & $2134(39.3)$ & $3294(60.7)$ & $5428(90.5)$ & & \\
\hline Hindu & $275(52.8)$ & $246(47.2)$ & $521(8.7)$ & & \\
\hline Other & $29(55.8)$ & $23(44.2)$ & $52(0.9)$ & & \\
\hline Maternal age & & & & 331.40 & $<0.001$ \\
\hline $15-24$ & $1117(32.8)$ & $2292(67.2)$ & $3409(56.8)$ & & \\
\hline $25-34$ & $1247(55.2)$ & $1014(44.8)$ & $2261(37.7)$ & & \\
\hline $35-49$ & $74(22.3)$ & $258(77.7)$ & $332(5.5)$ & & \\
\hline Maternal BMI $\left(\mathrm{kg} / \mathrm{m}^{2}\right)$ & & & & 66.01 & $<0.001$ \\
\hline Underweight $(\leq 18.50)$ & $290(35.0)$ & $538(65.0)$ & $828(13.8)$ & & \\
\hline Normal (18.51-25.00) & $1382(38.2)$ & $2232(61.8)$ & $3614(60.2)$ & & \\
\hline Overweight/Obese (> 25.00) & $765(49.1)$ & $792(50.9)$ & $1557(26.0)$ & & \\
\hline Maternal education level & & & & 527.17 & $<0.001$ \\
\hline No education & $76(27.8)$ & $197(72.2)$ & $273(4.6)$ & & \\
\hline Primary & $441(29.7)$ & $1043(70.3)$ & $1484(24.7)$ & & \\
\hline Secondary & $1117(36.1)$ & $1977(63.9)$ & $3094(51.6)$ & & \\
\hline Higher & $803(69.9)$ & $345(30.1)$ & $1148(10.1)$ & & \\
\hline Current working status & & & & 25.13 & $<0.001$ \\
\hline Not Working & $1623(43.1)$ & $2145(56.9)$ & $3768(62.8)$ & & \\
\hline Working & $815(36.5)$ & $1418(63.5)$ & $2233(37.2)$ & & \\
\hline Husband's education level & & & & 295.74 & $<0.001$ \\
\hline No education & $209(29.7)$ & $495(50.3)$ & $704(11.7)$ & & \\
\hline Primary & $651(33.4)$ & $1298(66.6)$ & $1949(32.5)$ & & \\
\hline Secondary & $826(39.0)$ & $1293(61.0)$ & $2119(35.3)$ & & \\
\hline Higher & $752(61.2)$ & $476(38.8)$ & $1228(20.5)$ & & \\
\hline Husband's occupation & & & & 58.57 & $<0.001$ \\
\hline Agriculture & $350(32.7)$ & $720(67.3)$ & $1070(17.8)$ & & \\
\hline Business & $573(44.7)$ & $710(55.3)$ & $1283(21.4)$ & & \\
\hline Service & $1285(43.3)$ & $1682(56.7)$ & $2967(49.4)$ & & \\
\hline Other & $230(33.8)$ & $451(66.2)$ & $681(11.3)$ & & \\
\hline Wealth status & & & & 207.02 & $<0.001$ \\
\hline Poor & $696(30.4)$ & $1591(69.6)$ & $2287(38.1)$ & & \\
\hline Middle & $462(38.8)$ & $729(61.2)$ & $1191(19.8)$ & & \\
\hline Rich & $1280(50.7)$ & $1243(49.3)$ & $2523(42.0)$ & & \\
\hline Watching TV & & & & 75.25 & $<0.001$ \\
\hline
\end{tabular}


Table 1 (continued)

\begin{tabular}{|c|c|c|c|c|c|}
\hline \multirow[t]{2}{*}{ Variables } & \multicolumn{2}{|c|}{ High-risk fertility problem } & \multirow[t]{2}{*}{ Total (\%) } & \multirow[t]{2}{*}{ Chi-square value } & \multirow[t]{2}{*}{ P-value } \\
\hline & No & Yes & & & \\
\hline No & $658(32.8)$ & $1342(67.2)$ & 1998 (33.3) & & \\
\hline Yes & $1781(44.5)$ & $2221(55.5)$ & $4002(66.7)$ & & \\
\hline Sex of the child & & & & 0.99 & 0.332 \\
\hline Male & $1289(41.2)$ & $1838(58.8)$ & $3127(52.1)$ & & \\
\hline Female & $1148(40.0)$ & $1725(60.0)$ & $2873(47.9)$ & & \\
\hline Types of toilet use & & & & 65.30 & $<0.001$ \\
\hline Unimproved & $472(31.7)$ & $1017(68.3)$ & $1489(24.8)$ & & \\
\hline Improved & 1965 (43.6) & $2546(42.4)$ & $4511(75.2)$ & & \\
\hline
\end{tabular}

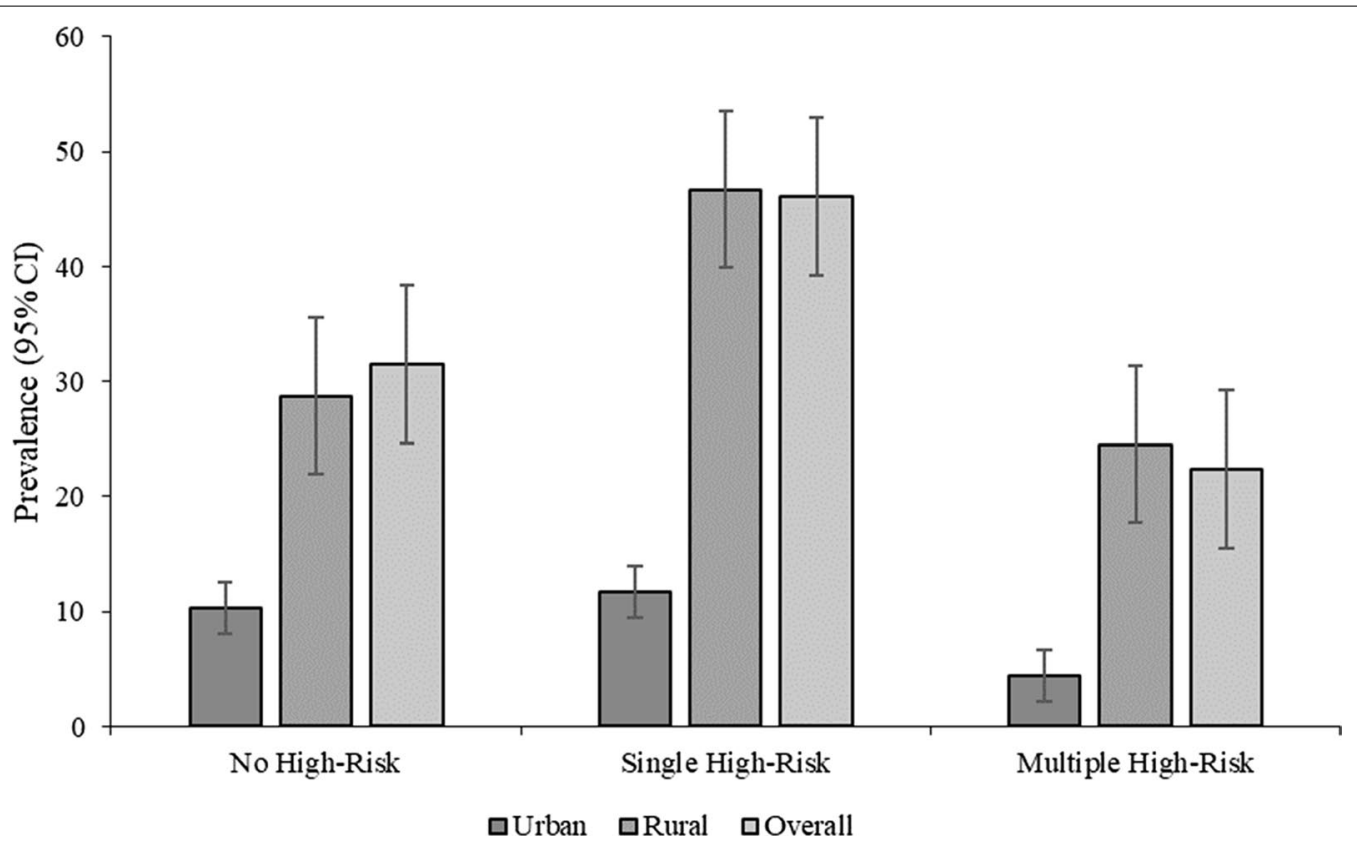

Fig. 1 Prevalence of HRFB by place of residence

$(\mathrm{AOR}=10.79,95 \%$ CI 5.67-18.64, $\mathrm{p}<0.001)$. Women who did not presently use contraceptive methods were 1.37 times more likely to have HRFB compared to their counterparts $(\mathrm{AOR}=1.37,95 \%$ CI 1.24-1.81, $\mathrm{p}<0.001)$. The odds of HRFB disproportionately distributed across the divisional regions. On the other hand, women aged 25 to 34, having secondary and higher education level; partner's higher-level education reduced the odds of high HRFB (Table 3).

\section{Discussion}

This study showed that $67.7 \%$ of women had HRFB, of which $45.6 \%$ were in single high-risk category and $22.1 \%$ women have had multiple high-risk categories. This high prevalence rate demonstrates that HRFB are all too common in Bangladesh, potentially endangering the health of the country's women. We found that women who were Muslims, age above 35 years, having normal childbirth, having low literacy level, having unwanted pregnancies, not using birth control methods were at increased risk of having HRFB.

When compared to women who have never had any formal education, those with a higher level of education had a lower likelihood of high-risk fertility behaviour. This result was supported by the previously conducted studies [22, 25-27]. The reason for this could be having no formal education impacts on work status and leads to lower income and independence all of which affect 


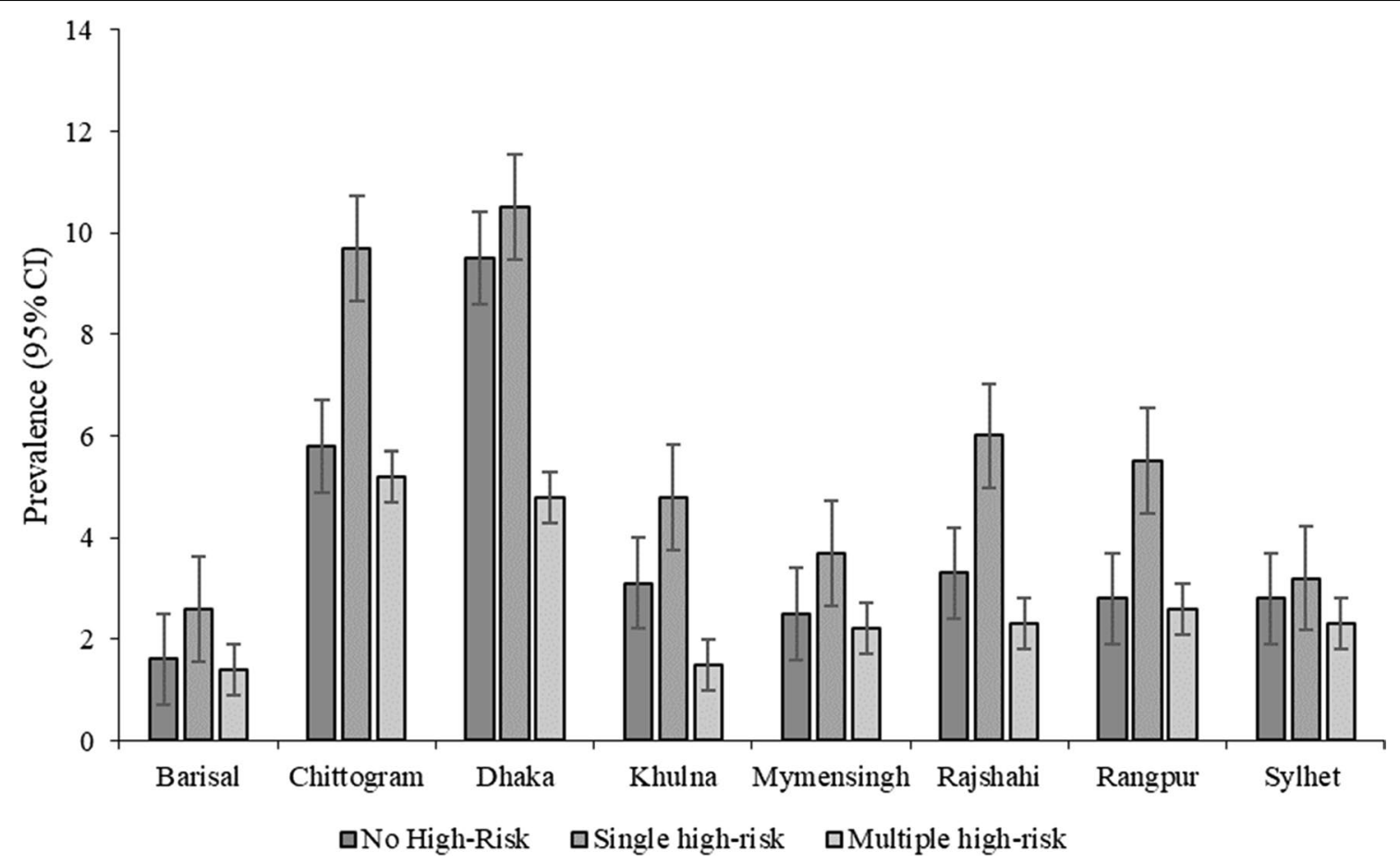

Fig. 2 Prevalence of HRFB by administrative regions

Table 2 Bivariate distribution of high-risk fertility behaviour of respondents across different reproductive factors $(n=7757)$

\begin{tabular}{|c|c|c|c|c|c|}
\hline \multirow[t]{2}{*}{ Variables } & \multicolumn{2}{|c|}{ High-risk fertility } & \multirow[t]{2}{*}{ Total (\%) } & \multirow[t]{2}{*}{ Chi-square value } & \multirow[t]{2}{*}{ P-Value } \\
\hline & No & Yes & & & \\
\hline Place of delivery & & & & 128.14 & $<0.001$ \\
\hline Facility Birth & $1056(51.4)$ & $999(48.6)$ & $2055(54.3)$ & & \\
\hline Home & $573(33.1)$ & $1158(66.9)$ & $1731(45.7)$ & & \\
\hline Type of delivery & & & & 136.005 & $<0.001$ \\
\hline Normal & $952(35.3)$ & $1747(64.7)$ & $2699(63.8)$ & & \\
\hline Caesarean & $821(53.7)$ & $708(46.3)$ & $1529(36.2)$ & & \\
\hline ANC seeking $(n=4605)$ & & & & 27.47 & $<0.001$ \\
\hline No & $61(26.8)$ & $167(73.2)$ & $228(8.1)$ & & \\
\hline Yes & $1535(44.5)$ & $1913(55.5)$ & $3448(91.9)$ & & \\
\hline Pregnancy wanted $(n=4814)$ & & & & 61.11 & $<0.001$ \\
\hline Then & $1431(45.2)$ & $1732(54.8)$ & $3163(83.6)$ & & \\
\hline Later & $185(35.9)$ & $330(64.1)$ & $515(13.6)$ & & \\
\hline No more & $12(11.2)$ & $95(88.8)$ & $107(2.8)$ & & \\
\hline Contraceptive use & & & & 11.34 & $<0.001$ \\
\hline Yes & $1596(39.2)$ & $2479(60.8)$ & $4075(67.9)$ & & \\
\hline No & $842(43.2)$ & $1083(56.3)$ & $1925(32.1)$ & & \\
\hline
\end{tabular}

purchasing power, taking proper care of mother during pregnancy, visiting ANC. Women who receive formal education had better knowledge and awareness about self-health consciousness, proper diet and thus lead to low odds of HRFB.

In this study, visiting ANC was found to be facilitating factor for reducing the odds of high HRFB. This is 
Table 3 Factors associated with high-risk fertility behaviour among women: BDHS 2017-18

\begin{tabular}{|c|c|c|c|c|}
\hline & UOR $(95 \% \mathrm{Cl})$ & P-value & AOR $(95 \mathrm{Cl})$ & P-value \\
\hline \multicolumn{5}{|l|}{ Administrative regions } \\
\hline Barishal & $1.20(0.99-1.46)$ & 0.062 & $1.88(1.29-2.75)$ & 0.001 \\
\hline Chottogram & $1.29(1.09-1.53)$ & 0.003 & $2.17(1.63-2.89)$ & $<0.001$ \\
\hline Dhaka & $0.83(0.70-0.98)$ & 0.027 & $1.27(0.96-1.68)$ & 0.094 \\
\hline Khulna & $0.98(0.81-1.18)$ & 0.842 & $2.11(1.51-2.95)$ & $<0.001$ \\
\hline Mymensingh & $1.22(1.01-1.47)$ & 0.037 & $1.55(1.11-2.17)$ & 0.010 \\
\hline Rajshahi & $1.25(1.03-1.56)$ & 0.022 & $1.91(1.39-2.63)$ & $<0.001$ \\
\hline Rangpur & $1.36(1.23-1.65)$ & 0.001 & $2.22(1.60-3.09)$ & $<0.001$ \\
\hline Sylhet (Ref.) & 1 & & 1 & \\
\hline \multicolumn{5}{|l|}{ Place of residence } \\
\hline Urban (Ref.) & 1 & & 1 & \\
\hline Rural & $1.59(1.44-1.76)$ & $<0.001$ & $0.87(0.73-1.03)$ & 0.101 \\
\hline \multicolumn{5}{|l|}{ Religion } \\
\hline Islam & $2.23(1.25-3.98)$ & 0.007 & $5.52(2.25-13.52)$ & $<0.001$ \\
\hline Hindu & $1.14(0.63-2.08)$ & 0.660 & $2.50(1.90-6.30)$ & 0.053 \\
\hline Other (Ref.) & 1 & & 1 & \\
\hline \multicolumn{5}{|l|}{ Maternal age } \\
\hline 25-34 (Ref.) & 1 & & 1 & \\
\hline $15-24$ & $1.29(1.17-1.42)$ & $<0.001$ & $0.19(0.10-0.30)$ & $<0.001$ \\
\hline $35-49$ & $3.79(2.94-4.88)$ & $<0.001$ & $6.42(3.95-10.42)$ & $<0.001$ \\
\hline \multicolumn{5}{|l|}{ Maternal BMI $\left(\mathrm{kg} / \mathrm{m}^{2}\right)$} \\
\hline Underweight ( $\leq 18.50$ ) (Ref.) & 1 & & 1 & \\
\hline Normal (18.51-25.00) & $0.90(0.78-1.04)$ & 0.156 & $1.05(0.83-1.35)$ & 0.652 \\
\hline Overweight/Obese $(\geq 25.00)$ & $0.61(0.52-0.71)$ & $<0.001$ & $1.03(0.87-1.23)$ & 0.730 \\
\hline \multicolumn{5}{|l|}{ Maternal education level } \\
\hline No education (Ref.) & 1 & & 1 & \\
\hline Primary & $0.77(0.60-0.99)$ & 0.041 & $7.05(4.68-10.63)$ & $<0.001$ \\
\hline Secondary & $0.80(0.36-0.58)$ & $<0.001$ & $5.85(4.52-7.581)$ & $<0.001$ \\
\hline Higher & $0.90(0.44-0.98)$ & $<0.001$ & $0.93(0.80-1.08)$ & 0.328 \\
\hline \multicolumn{5}{|l|}{ Current working status } \\
\hline Not Working (Ref.) & 1 & & 1 & \\
\hline Working & $1.48(1.34-1.63)$ & $<0.001$ & $0.99(0.85-1.16)$ & 0.908 \\
\hline \multicolumn{5}{|l|}{ Husbands education level } \\
\hline No education (Ref.) & 1 & & 1 & \\
\hline Primary & $0.71(0.60-0.85)$ & $<0.001$ & $1.59(1.17-2.15)$ & 0.003 \\
\hline Secondary & $0.46(0.39-0.54)$ & $<0.001$ & $1.31(1.04-1.66)$ & 0.022 \\
\hline Higher & $0.16(0.13-0.19)$ & $<0.001$ & $0.39(0.12-0.72)$ & 0.001 \\
\hline \multicolumn{5}{|l|}{ Husband occupation } \\
\hline Agriculture (Ref.) & 1 & & 1 & \\
\hline Business & $0.53(0.45-0.62)$ & $<0.001$ & $1.02(0.78-1.30)$ & 0.894 \\
\hline Service & $0.46(0.40-0.53)$ & $<0.001$ & $1.01(0.78-1.30)$ & 0.965 \\
\hline Other & $0.89(0.73-1.08)$ & 0.230 & $1.02(0.80-1.22)$ & 0.791 \\
\hline \multicolumn{5}{|l|}{ Wealth status } \\
\hline Poor & $1.69(1.47-1.95)$ & $<0.001$ & $1.07(0.85-1.31)$ & 0.538 \\
\hline Middle (Ref.) & 1 & & 1 & \\
\hline Rich & $0.57(0.50-0.65)$ & $<0.001$ & $1.01(0.83-1.23)$ & 0.938 \\
\hline \multicolumn{5}{|l|}{ Watching TV } \\
\hline No (Ref.) & 1 & & 1 & \\
\hline Yes & $0.51(0.46-0.56)$ & $<0.001$ & $0.89(0.78-1.07)$ & 0.076 \\
\hline
\end{tabular}


Table 3 (continued)

\begin{tabular}{|c|c|c|c|c|}
\hline & UOR $(95 \% \mathrm{Cl})$ & P-value & AOR $(95 \mathrm{Cl})$ & P-value \\
\hline \multicolumn{5}{|l|}{ Types of toilet use } \\
\hline Unimproved (Ref.) & 1 & & 1 & \\
\hline Improved & $0.47(0.42-0.53)$ & $<0.001$ & $0.97(0.89-1.24)$ & 0.561 \\
\hline \multicolumn{5}{|l|}{ Place of delivery } \\
\hline Home & $0.38(0.33-0.42)$ & $<0.001$ & $0.78(0.72-1.17)$ & 0.104 \\
\hline Facility Birth (Ref.) & 1 & & 1 & \\
\hline \multicolumn{5}{|l|}{ Type of delivery } \\
\hline Normal & $2.71(2.41-3.06)$ & $<0.001$ & $1.47(1.22-1.69)$ & 0.003 \\
\hline Caesarean (Ref.) & 1 & & 1 & \\
\hline \multicolumn{5}{|l|}{ ANC seeking } \\
\hline No (Ref.) & 1 & & 1 & \\
\hline Yes & $0.34(0.27-0.45)$ & $<0.001$ & $0.77(0.76-1.16)$ & 0.114 \\
\hline \multicolumn{5}{|c|}{ Pregnancy wanted $(n=4814)$} \\
\hline Then (Ref.) & 1 & & 1 & \\
\hline Later & $1.44(1.20-1.74)$ & $<0.001$ & $1.26(0.94-1.65)$ & 0.292 \\
\hline No More & $16.29(9.52-27.89)$ & $<0.001$ & $10.79(5.67-18.64)$ & $<0.001$ \\
\hline \multicolumn{5}{|l|}{ Contraceptive use } \\
\hline No & $1.24(1.12-1.38)$ & $<0.001$ & $1.37(1.24-1.81)$ & $<0.001$ \\
\hline Yes (Ref.) & 1 & & 1 & \\
\hline
\end{tabular}

probably due to the fact that antenatal care provides opportunities to reach pregnant women with a variety of interventions that may be essential to their health and well-being $[28,29]$, thus they were more likely to receive information regarding importance of routine check-up, maternal nutrition, delivery complications and risk of having HRFB. On the other hand, women, who did not have ANC follow-ups for their recent children, had more probability to engage in risky reproductive behaviours. Family planning for extending the time between births was discussed during postnatal care counseling. As a result, decreased ANC seeking during pregnancy may have a role in HRFB.

Another important finding from this study is women who had a history of caesarean delivery were less likely to have high-risk fertility behavior. There are some other studies related to the association between type of delivery and subsequent fertility $[30,31]$ which have similar results. The reason behind this may be women who have their babies by cesarean section were less likely to have more children than women who have their babies vaginally and also cesarean section delivery was followed by a higher likelihood of actively contraception after that birth, which may lead to low odds of HRFB.

This study revealed that, HRFB was more likely to occur among women who had never taken contraception compared to those who used which is in line with previously did studies elsewhere [32,33]. One of the goals of contraception is to increase the birth interval and reduce unplanned pregnancies. Women who had unwanted pregnancies were more likely to engage in high-risk reproductive behaviour than those who had previous desired pregnancies. It may be the result of not using contraceptive methods by the women who experienced unwanted pregnancies. This result also corroborates with a study conducted in Nigeria [25].

Moreover, religious belief also did affect maternal HRFB. Our study revealed that the women who were Muslims, have increased odds of HRFB compared with other religious believers. This finding was in line with an Indian study [34], where the author argued that Muslim women are less willing to use contraceptive methods, family planning and they prefer temporary methods over sterilisation, these could be plausible reasons why Muslim women in Bangladesh were at higher risk of having HRFB.

Evidence suggests that maternal age of 35-49 have the higher odds of HRFB than their counterparts. Similar result was found in other study where the author concluded that pregnancy at later stage is associated with significant increases in maternal risks and complications $[35,36]$ which leads to adverse outcome for both the mother and the child.

Furthermore, high-risk fertility behaviours were found more than double among women in Rangpur, a northern region in Bangladesh, compared to the women who live in Sylhet. This is probably due to the fact that women in remote locations may stay behind in terms 
of utilizing reproductive health services, such as ANC, poor family planning adopted rates related to religious beliefs and community attitudes, as well as having poor literacy levels. However, this inequity in utilizing reproductive health facilities among different regions in Bangladesh should be minimize to reduce the odds of HRFB. This analysis may lead to important inferences that may help to lower maternal high-risk fertility behaviour and can be useful and relevant in areas where HRFB is ubiquitous. The strengths and limitations of this study have been well-recognised. The study employed the recently published BDHS 2017-18 data which had a large country representative sample size, allowing the findings to be more generalisable. Moreover, appropriate statistical technique applied in the analysis can be used to find probable components and their relationships. However, the study has some limitations. For instance, due to cross-sectional data, outcomes and predictors variables were collected at a point of time; therefore, causality cannot be established. In addition, some important factors, such as dietary factors, physical activity and maternal comorbidity histories are not taken into consideration due to unavailability in the original dataset, but these factors may have been associated with HRFB.

\section{Conclusions}

This study highlighted the pervasiveness of maternal high-risk fertility behaviour among Bangladeshi reproductive aged women. Several significant protective factors, such as maternal and partners' higher education were associated with lower HRFB. In contrast, being Muslims, age 35 to 49 years, having normal childbirth, having unwanted pregnancies, and not using any birth control tools may increase risk of having HRFB for women. Thus, findings from the study identify the need to develop an intervention; especially focusing on Bangladeshi Muslim women aged 35-49 years to reduce highrisk fertility behaviour. Furthermore, the government of Bangladesh and stakeholders (e.g., NGOs, INGOs) should work jointly to prevent early marriage of women and to enhance awareness and proper education to reduce the high-risk fertility behaviour.

\section{Acknowledgements}

The authors would like to thank the Demographic and Health Survey for providing the data freely. Md. Ashfikur Rahman is the Senior Author of this article.

\section{Authors' contributions}

$\mathrm{MHH}$ and MAR conceptualised the research idea and study design. MAR explored the data and performed analysis with the guidelines of $\mathrm{MHH} . \mathrm{MHH}$, SK, HRH checked and validated the results. MHH, MAR, HOR drafted the manuscript with the support from MHH. SK, HRH, SKC critically reviewed the manuscript for scientific coherence. MAR supervised the whole study. All authors read and approved the final manuscript.

\section{Funding}

This research did not receive any specific grant from any financial and nonfinancial sectors.

\section{Availability of data and materials}

This study used publicly available Demographic and Health Surveys Program datasets from Bangladesh which can be freely obtained from https://dhspr ogram.com/. As a third-party user we don't have permission to share the data publicly in any platforms.

\section{Declarations}

\section{Ethics approval and consent to participate}

The current study involved analyzing secondary data, which is publicly accessible at www.dhsprogram.com and free of cost upon appropriate application. The ICF Institutional Review Board and Ethical Review Board of Ministry of Health approved the data collection and survey process. Therefore, further ethical approval was not needed. The current study relied on publicly available data sources that had already been ethically approved for the primary investigations, so no additional ethical approval was required.

\section{Consent for publication}

Not applicable.

\section{Competing interests}

None of the authors declares any conflict of interest.

\section{Author details}

${ }^{1}$ Development Studies Discipline, Khulna University, Khulna 9208, Bangladesh. ${ }^{2}$ Statistics Discipline, Khulna University, Khulna 9208, Bangladesh. ${ }^{3}$ School of Public Health, Southeast University, Nanjing 210009, China. ${ }^{4}$ Faculty of Nutrition and Food Science, Patuakhali Science and Technology University, Dumki, Patuakhali 8602, Bangladesh. ${ }^{5}$ Department of Community Health Sciences, Max Rady College of Medicine, University of Manitoba, Winnipeg, MB, Canada. ${ }^{6}$ Sociology Discipline, Khulna University, Khulna 9208, Bangladesh. ${ }^{7}$ Development Studies Discipline, Khulna University, Khulna 9208, Bangladesh.

Received: 6 October 2021 Accepted: 19 December 2021

Published online: 21 January 2022

\section{References}

1. Hammarberg K, Zosel R, Comoy C, Robertson S, Holden C, Deeks M, et al. Fertility-related knowledge and information-seeking behaviour among people of reproductive age: a qualitative study. Hum Fertil. 2017;20:88-95

2. Khan T, Ali Khan RE. Fertility behaviour of women and their household characteristics: a case study of Punjab, Pakistan. J Hum Ecol. 2010;30:11-7.

3. Amir-ud-Din R, Naz L, Rubi A, Usman M, Ghimire U. Impact of high-risk fertility behaviours on underfive mortality in Asia and Africa: evidence from Demographic and Health Surveys. BMC Pregnancy Childbirth. 2021;21:1-39. https://doi.org/10.1186/s12884-021-03780-y.

4. Pal SK, Shekhar C. Examining the role of high-risk fertility behaviour in chronic undernutrition among Indian married women age 15-49. Clin Epidemiol Glob Heal. 2021;11: 100739. https://doi.org/10.1016/j.cegh. 2021.100739

5. Tadesse ZT, Azanaw MM, Asmare Y, Gelaye KA. Geographically vary determinants of High-Risk Fertility Behavior among Reproductive age women in Ethiopia. Geographically Weight Regres Anal. 2020. https://doi.org/10. 21203/rs.2.21783/v1.

6. Fadl N, Haile Z, Ice G. Association between maternal high-risk fertility behavior and anemia among reproductive age women in Ethiopia. 2020; 1-20. https://doi.org/10.21203/rs.3.rs-15729/v1.

7. Rahman M, Islam MJ, Haque SE, Saw YM, Haque MN, Duc NHC, et al. Association between high-risk fertility behaviours and the likelihood of chronic undernutrition and anaemia among married Bangladeshi women of reproductive age. Public Health Nutr. 2017;20:305-14.

8. Khan MA, Khan N, Rahman O, Mustagir G, Hossain K, Islam R, et al. Trends and projections of under-5 mortality in Bangladesh including the effects 
of maternal high-risk fertility behaviours and use of healthcare services. PLoS One. 2021;16:e0246210.

9. Bangladesh Bureau of Statistics (BBS). Bangladesh Sample Vital Statistics 2020. 2020.

10. Bhowmik J, Biswas RK, Hossain S. Child marriage and adolescent motherhood: a nationwide vulnerability for women in Bangladesh. Int J Environ Res Public Health. 2021. https://doi.org/10.3390/ijerph18084030.

11. Alam MDR, Khan MDN, Cherri Z, Kumar RT, Rahman MDM. Child bearing age and pregnancy outcomes in Bangladesh: a multilevel analysis of a nationwide population-based survey. Prim Heal Care Open Access. 2018. https://doi.org/10.4172/2167-1079.1000294.

12. Favilli A, Pericoli S, Acanfora MM, Bini V, Di Renzo GC, Gerli S. Pregnancy outcome in women aged 40 years or more. J Matern Neonatal Med. 2012:25:1260-3. https://doi.org/10.3109/14767058.2011.643327.

13. Fretts RC, Usher RH. Causes of fetal death in women of advanced maternal age. Obstet Gynecol. 1997;89:40-5. https://doi.org/10.1016/S00297844(96)00427-9.

14. Bhalotra S, Van Soest A. Birth-spacing, fertility and neonatal mortality in India: dynamics, frailty, and fecundity. J Econom. 2008;143:274-90.

15. Geronimus AT. On teenage childbearing and neonatal mortality in the United States. Popul Dev Rev. 1987;13:245-79.

16. Mozumder ABMKA, Kane TT, Levin A, Ahmed S. The effect of birth interval on malnutrition in Bangladeshi infants and young children. J Biosoc Sci. 2000:32:289-300

17. Rahman M, Hosen A, Khan MA. Association between maternal high-risk fertility behavior and childhood morbidity in Bangladesh: a nationally representative cross-sectional survey. Am J Trop Med Hyg. 2019;101:929.

18. Raj A, Saggurti N, Balaiah D, Silverman JG. Prevalence of child marriage and its effect on fertility and fertility-control outcomes of young women in India: a cross-sectional, observational study. Lancet. 2009;373:1883-9.

19. Fronczak N, Antelman G, Moran AC, Caulfield LE, Baqui AH. Deliveryrelated complications and early postpartum morbidity in Dhaka, Bangladesh. Int J Gynecol Obstet. 2005;91:271-8.

20. Rasooly MH. The effect of birth intervals on causes of under-five mortality in Afghanistan. ICF International; 2013.

21. Mishra SK, Ram B, Singh A, Yadav A. Birth order, stage of infancy and infant mortality in India. J Biosoc Sci. 2018;50:604-25.

22. Rahman M, Haque SE, Zahan S, Islam J, Rahman M, Asaduzzaman MD, et al. Maternal high-risk fertility behavior and association with chronic undernutrition among children under age 5 y in India, Bangladesh, and Nepal: do poor children have a higher risk? Nutrition. 2018;49:32-40.

23. National Institute of Population Research and Training (NIPORT), ICF International. Bangladesh Demographic and Health Survey 2017-18. Dhaka, Bangladesh, and Rockville, Maryland; 2020. https://dhsprogram.com/ pubs/pdf/PR104/PR104.pdf

24. World Health Organization. BMI Classification 2019. 2019 (cited 18 Oct 2019). http://apps.who.int/bmi/index.jsp?introPage=intro_3.html.

25. Adiri F, Ibrahim HI, Ajayi V, Sulayman HU, Yafeh AM, Ejembi CL. Fertility behaviour of men and women in three communities in Kaduna state. Nigeria Afr J Reprod Health. 2010;14:97-105.

26. Kulu H, Boyle PJ. High fertility in city suburbs: compositional or contextual effects? Eur J Popul Eur Démographie. 2009;25:157-74.

27. Gurmu E, Tariku D. Correlates of high risk fertility behaviour in Ethiopia: a multilevel analysis of the 2011 Ethiopian demographic and health survey data. J Heal Med Nurs. 2017;39:86-95.

28. Kumera G, Gedle D, Alebel A, Feyera F, Eshetie S. Undernutrition and its association with socio-demographic, anemia and intestinal parasitic infection among pregnant women attending antenatal care at the University of Gondar Hospital, Northwest Ethiopia. Matern Heal Neonatol Perinatol. 2018:4:1-10.

29. Tessema ZT, Tamirat KS. Determinants of high-risk fertility behavior among reproductive-age women in Ethiopia using the recent Ethiopian Demographic Health Survey: a multilevel analysis. Trop Med Health [Internet]. 2020:48:93. Available from: https://doi.org/10.1186/ s41182-020-00280-1.

30. Evers EC, McDermott KC, Blomquist JL, Handa VL. Mode of delivery and subsequent fertility. Hum Reprod. 2014;29:2569-74.

31. Gurol-Urganci I, Cromwell DA, Mahmood TA, van der Meulen JH, Templeton A. A population-based cohort study of the effect of Caesarean section on subsequent fertility. Hum Reprod. 2014;29:1320-6.
32. Brown W, Ahmed S, Roche N, Sonneveldt E, Darmstadt GL. Impact of family planning programs in reducing high-risk births due to younger and older maternal age, short birth intervals, and high parity. Seminars in perinatology. Elsevier; 2015. pp. 338-344.

33. Rutstein SO, Winter R. The effects of fertility behavior on child survival and child nutritional status: evidence from the demographic and health surveys, 2006 to 2012. ICF International; 2014.

34. Mishra VK. Muslim/non-Muslim differentials in fertility and family planning in India. 2004.

35. Luke B, Brown MB. Elevated risks of pregnancy complications and adverse outcomes with increasing maternal age. Hum Reprod. 2007;22:1264-72.

36. Ludford I, Scheil W, Tucker G, Grivell R. Pregnancy outcomes for nulliparous women of advanced maternal age in South Australia, 1998-2008. Aust New Zeal J Obstet Gynaecol. 2012;52:235-41.

\section{Publisher's Note}

Springer Nature remains neutral with regard to jurisdictional claims in published maps and institutional affiliations.
Ready to submit your research? Choose BMC and benefit from:

- fast, convenient online submission

- thorough peer review by experienced researchers in your field

- rapid publication on acceptance

- support for research data, including large and complex data types

- gold Open Access which fosters wider collaboration and increased citations

- maximum visibility for your research: over $100 \mathrm{M}$ website views per year

At BMC, research is always in progress.

Learn more biomedcentral.com/submissions 